\title{
Aesthetic Quality Experiences (AQE) as a Means of Improving Reading and Writing: A Case Study
}

\author{
Barbara Pons, Isabel Alvarez* \\ Department of Systematic and Social Pedagogy, Autonomous University of Barcelona, Spain
}

Received July 20, 2020; Revised August 22, 2020; Accepted September 29, 2020

\section{Cite This Paper in the following Citation Styles}

(a): [1] Barbara Pons, Isabel Alvarez, "Aesthetic Quality Experiences (AQE) as a Means of Improving Reading and Writing: A Case Study," Universal Journal of Educational Research, Vol. 8, No. 11, pp. 5376 - 5387, 2020. DOI: 10.13189/ujer.2020.081140.

(b): Barbara Pons, Isabel Alvarez (2020). Aesthetic Quality Experiences (AQE) as a Means of Improving Reading and Writing: A Case Study. Universal Journal of Educational Research, 8(11), 5376 - 5387. DOI: 10.13189/ujer.2020.081140.

Copyright $@ 2020$ by authors, all rights reserved. Authors agree that this article remains permanently open access under the terms of the Creative Commons Attribution License 4.0 International License

\begin{abstract}
This study presents the way in which the creation of aesthetic quality experiences as objects of innovation contributes to improving the reading and writing skills of children between 3 and 5 years old in Catalonia, Spain. The concept of aesthetic quality experiences was developed [1]. These experiences possess certain distinctive features, among which is the fact that they are highly significant for children, and therefore enhance their motivation as they focus on the skill they are learning. The tests employed are based on a qualitative approach whereby, using a specific rubric, they measure the children's' phonological awareness and reading skills. The sample consists of 52 children at the same school. The study presents the results obtained, and shows an improvement both in reading and writing, assuming that learning is mediated through significant Experiences. In conclusion we can state that all the pupils show improvements in several respects, even children with some learning difficulties, which suggests that we should continue to apply aesthetic quality experiences throughout nursery and primary education.
\end{abstract}

Keywords Experiences, Reading, Writing

\section{Introduction}

In the 21st century, the ability to read is indispensable for anyone who wants to become an active member of society. According to statistics show that $80 \%$ of children with learning difficulties also have problems reading, and with speaking or with language in general [2]. Problems with reading are frequent among school-age children to the point where the WHO (2001) included reading among its diagnostic criteria for determining learning difficulties. There are different frameworks for the treatment of difficulties associated with reading and writing, but $70 \%$ of these difficulties originate in reading and writing problems as such.

Reading is the basis of all of a child's learning from the very beginning. The debate centres around how and when this learning process should begin, whether or not the cognitive level of each child should be taken into account and how the general methodology so that the process develops their potential to the full. The method whereby reading is learnt at school is divided into the three school years that comprise early primary education, which is the stage that this study focuses on:

At $\mathrm{P}^{1}$, letters are introduced, albeit not all of them. That is to say, during the school year, each pupil learns to write their name and to recognise the letters that are contained in it (especially the first letter). For this reason, all the significant elements of the class show the child's name, for example their desks, as the photos illustrate. Depending on the class, and therefore on the names of the children, it

1 P3, P4 and P5 in the Spanish system correspond to P1, P2 and P3 respectively. 
might be necessary to introduce concepts like the "deceptive U sound" in the case of a name like "Oriol", in other words phonetic nuance is introduced wherever necessary, but only insofar as it affects the class in question.

At P4, all the letters of the alphabet, both vowels and consonants, are learnt, along with their sounds. In everyday class work, all the letters of the alphabet are represented by the image of an animal, a plant or an object beginning with that letter. In this class it has been observed that when the teacher tells them to pronounce the letters, they pronounce all of them, by name, the sound and the drawing used to represent it (for example, the "C" is pronounced "see", but is represented as the " $\mathrm{k}$ " sound in the word "cavall", the Catalan word for horse).

The method used to help pupils to learn how to read is phonetic nuance, whereby each of the sounds, in Catalan, has a particular nuance. This element is introduced in this school year so that it will be assimilated from then onwards. Dictations which focus attention on the pronunciation of letters are also used to work on sounds.

And, finally, the aim in P5 is to develop the mechanics of reading itself. To this end, the process is divided into the following stages:

1. Learning the letter, the syllable and the word. A weekly worksheet is created where all three are featured (taking account of phonetic nuance)

2. Dictations are used to focus on pronunciation (words or sentences)

3. Letters with phonetic nuance are introduced

4. The worksheets focus on phonetic nuance

5. Drawings are used to promote natural writing, and pupils are encouraged to describe the drawings in writing

Despite this, the work has failed to incorporate experiences of aesthetic quality, with the result that the individual abilities of each pupil have not been taken into account. This problem could be solved if the worksheets were personalised for each pupil, and based on their particular interests, so that the reading process would be motivating for them, and, at the same time it would stimulate comprehension as each pupil would be fully engaged and very attentive when reading about something that they are really interested in.

There are numerous studies, [3], [4], [5], [6], [7] and [8], among others, have demonstrated the links between the different predictors of reading efficiency (both in terms of the mechanics of reading and comprehension). But at present, these predictors are not being used actively with a view to modifying, if necessary, the different methods being used during learning so that it will become what referred to as Quality Educational Experience [1]; that is to say, that the method should be adapted to each child and, therefore, to each environment, so that the learning might be as motivating and significant as possible and, most importantly, that it will be enduring. The [9] states that the main aim of the stage is the development of the child's abilities in such a way that the (positive) emotions that arise during the learning process have a decisive influence on their progress.

This study offers sets out to show how reading and writing can become an experience of educational quality for children, which is why it will make use of neuroscientific principles to demonstrate the complexity of the phenomenon. It should also be pointed out that the study will be carried out in a semi-private school, and attention will be focused on the early primary stage. Participants will be drawn from this whole period, that is from the three years P3, P4 and P5. The research problem at the centre of this study would therefore be formulated as follows:

\section{How the creation of experiences of aesthetic quality can enhance the acquisition of the reading skills of children in P3, P4 and P5 in the classroom setting}

The following is a description of the overall aims underlying this study:

General Aim 1: To determine, via Phonological Awareness and RAN predictors, the level of success with which children at this stage of their primary education learn to read

General Aim 2: To determine how an Experience of Aesthetic Quality could benefit the learning process of reading and writing.

\section{Learning to read and write: Contributions from Neuroscience}

Neuroscience sets out to establish whether cognitive are valid for the interpretation of the scientific data obtained from two principal mechanisms, through the corroboration of neuroscientific studies and the use of neuroimaging. Functional Neuroimaging [10] is a very relevant tool used by neuroscientists to illustrate the fact that the neural system is made up of a series of interrelated cerebral components [11] There are different methods for learning to read and write [12] but not all of them is complex and systematised knowledge available with a view to establish measurable indicators. Additionally, these objectives also help us to take certain corrective measures in relation to the process of training pupils to read and write.

\section{Predictors and Factors which are Conductive to the Acquisition of Reading Skills}

There are many methods available for learning to read and write. All of them are equally valid, if they can be adapted to the situations of each pupil and to the surrounding environment [1]. That is to say, almost 
irrespective of the method, it must be remembered that there are a series of factors which influence the acquisition of reading, and whose relevance lies in the fact that awareness of them facilitates early detection of difficulties, and thus provides professional orientation for any intervention.

According to the factors can be grouped together under the following categories: 1) Neuropsychological, 2) Linguistic, 3) Intellectual 4) Socio-environmental and 5) Emotional [13]. Also distinguished between, on the one hand, predictors and on the other skills that would facilitate the initial development of reading, and divided them into five groups: oral language, a sufficient cognitive level, development of memory, perception and motor skills, motivational and attitudinal aspects and social variables [6]. Others concur and identify a series of predictors and facilitating skills. Among the predictors, it focuses particularly on the Rapid Automised Naming test (RAN) [14], [6].

Finally, in the report of the 2009, carried out by a range of experts, on precursive reading skills among children of 0 to 5 years old, identified 6 critical variables which ensure a successful development in reading competence, chief among which were Phonological Awareness (PA) and Rapid Automised Naming (RAN)[8]. According to, before learning begins children must have a minimum level of Phonological Awareness in order to be able to acquire reading skills, and these skills, simultaneously, will support the achievement of the most complex phonological tasks [15]. On the other hand, it should be pointed out that in recent years, the RAN test has become increasingly prominent in the development of reading competence, irrespective of the spelling system [16], [17], [18], [19]. Others [20] assign more importance to RAN than to PA. But there are also authors, [21], who found that reading errors were more associated with PA than with RAN. For that reason, it was decided to proceed on the basis of two main predictors: Phonological awareness (PA) and Rapid Automised Naming (RAN), as it is on these two that the test to be used with primary school children will be based.

\section{Phonological Awareness (PA)}

According to Phonological Awareness (PA) is one of the main precursors of the reading skill, along with naming speed, knowledge of the alphabet and phonological memory [22] and [23].

\section{Rapid Automised Naming (RAN)}

Some define RAN as a "mini-circuit" that is very similar to subsequent cerebral reading circuits that the child develops when they begin to read, as both systems involve closely interrelated cognitive processes. RAN tasks have great potential in predicting reading ability, presumably because performance in RAN and in reading is enhanced by shared cognitive processes [24].

\section{Aesthetic Quality Experiences (AQE) and Reading \& Writing Competence}

As outlined in the introduction, this study is intended to be an approach to reading and writing development, and how the latter can be an aesthetic quality experience for the children. For this reason, it is necessary first of all to situate the concept, so as later to be able to apply it to the study. The AQEs can be defined, as those experiences which enable the pupil to learn and, therefore, to grow and develop, and from which they receive fulness and satisfaction. According to the author, the problem inherent in education is that it separates the method of thinking from the material being studied. For this reason, the author states that when flexible and dynamic personal experiences are stimulated, an exchange always occurs between the living being and their environment [1].

Experience is based on connections and continuities and implies processes of reflection and inference; that is to say, experience and thought are two inseparably related terms [1]. Certain different concepts must be taken into account however. In the first place, according to the author, control of the environment is fundamental in order to avoid negative feedback from it. That is to say, negative feedback from the environment would entail erroneous and harmful learning, which it would later be difficult to modify and prevent from undermining later achievements [1].

In this sense, that education is impossible apart from the environment, but must provide a setting in which the innate potential of each pupil can be channeled towards the best possible outcomes. That is to say, the learning process has to be adapted to the inherent (physical and psychological) conditions of each pupil, their surrounding environment and their emotional state. Moreover, the setting should be simplified (it is normally more complex than immature children can understand) so that the process of learning to read and write will be adapted to the pupils' environment, will motivate them and provide experiences of educational quality, thus enabling them to evolve in a positive direction.[1]

Secondly, it argues that knowledge must be adapted to the pupil's age and be introduced, in the first place, in the form of play, after which effort is added and the focus becomes more and more specialised. In other words, when the programme of study is being formulated it is essential to take into account a) the intimate nature of the child's relationship with their environment, b) the importance of the teacher being a specialist in the material being learnt so that they can adequately adapt it to the abilities of each pupil, so that learning will become an experience of educational quality and c) the priority that must be given to essential knowledge (the mechanical efficiency of reading, writing, and an understanding of spelling and arithmetic) before focusing on the knowledge that will follow on from that as a refinement of these skills [1].

Dewey maintains that the sooner the immature child 
begins to be stimulated, through play and in a way that is adapted to the setting, the better the learning outcomes will subsequently be, as from the outset they are being given the tools they need to become autonomous thinkers and, especially, to learn to learn [1].

That is to say, perception, which is a capacity that their survival will depend and the basis of all their psychological processes, as this is what enables them to receive information, organise it and interpret it by giving it meaning, must be positive [25]. But throughout this process, it is important to remember that the baggage that each individual carries, even an immature child, must be taken into account, and also the environment that they inhabit, so that the learning process can be adapted both to the individual and to the group.

For this reason, not everyone will have the same perception of what constitutes an experience of aesthetic quality, but it is only an experience of aesthetic quality that gives meaning to the objects and events that an individual experiences, so it is only through the mode of aesthetic experience, which depends on a specific time and place, that immediate cooperation can occur, and the activity engaged in as something illuminating and irrepressible [26].

In our study we have created worksheets with aesthetic quality experiences in order to show how this concept sheds light on the two predictors that have been selected: Phonological Awareness and Rapid Automised Naming.

\section{Method}

For this study a descriptive qualitative methodology was applied. To be more precise, it is a Case Study [27] carried out within a primary school context (the case) analyzing three school academic years (sub-cases) because it focuses on a single context (the school) and seeks to analyse it thoroughly. The study develops throughout the early primary stage, the aim being to improve the methods for teaching reading and writing in these grades. The data is presented in numbers and percentage to be able to make comparisons with the number of students differed.

\subsection{Sample}

The sample consists of the whole population of the early primary stage in a semi-private school in Barcelona. It is made up of 17 children in P3 (10 boys and 7 girls), 15 in P4 ( 7 boys and 8 girls) and 20 in P5 (8 boys and 12 girls); that is to say, an overall of 52 pupils from 3 to 6 years old.

\subsection{Context}

The study was developed in a semi-private school in Barcelona with a very stable teaching staff. It is important to draw attention to this, because it means that, in the case of the particular sample in question, the teacher with least experience in this school has been working there for 15 years. This accumulated experience within the same school and stage has meant that they have been able to perfect, by combining and shuffling different procedures, and following their criteria and applying their wide-ranging experience, the method they use for pupils to learn to read and write.

\subsection{Instruments}

Six tests were carried out, classified under two groups:

The first of these tests, the RAN test, encompassed three subtests in the first of which there were questions about colours, in the second numbers and in the third, letters. The questions were asked in this order because it was felt that the first set of questions related to something that children at this stage are familiar with, and it was better to begin with something that would generate confidence for later stages.

In the second group, relating to Phonological Awareness, there were two tests. The first involved identifying letters or reading some words (depending on the year) and finally, under Aesthetic Quality Experience, the children were asked to explain what these words meant for them, as we felt that AQE should also be tested in this block. The following image shows samples of the worksheets for each of the three years.

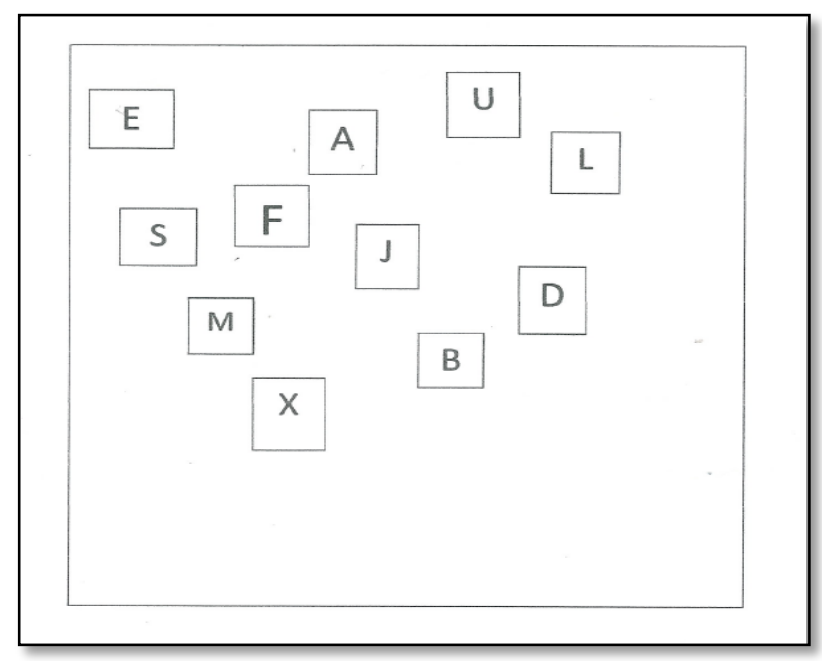

Sample 1: P3 RAN test 


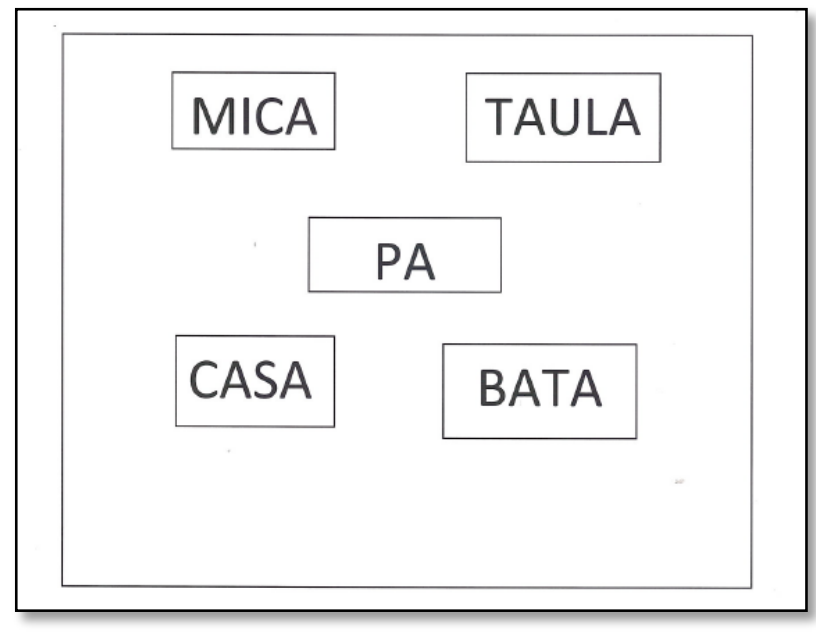

Sample 2: P3 PA test.

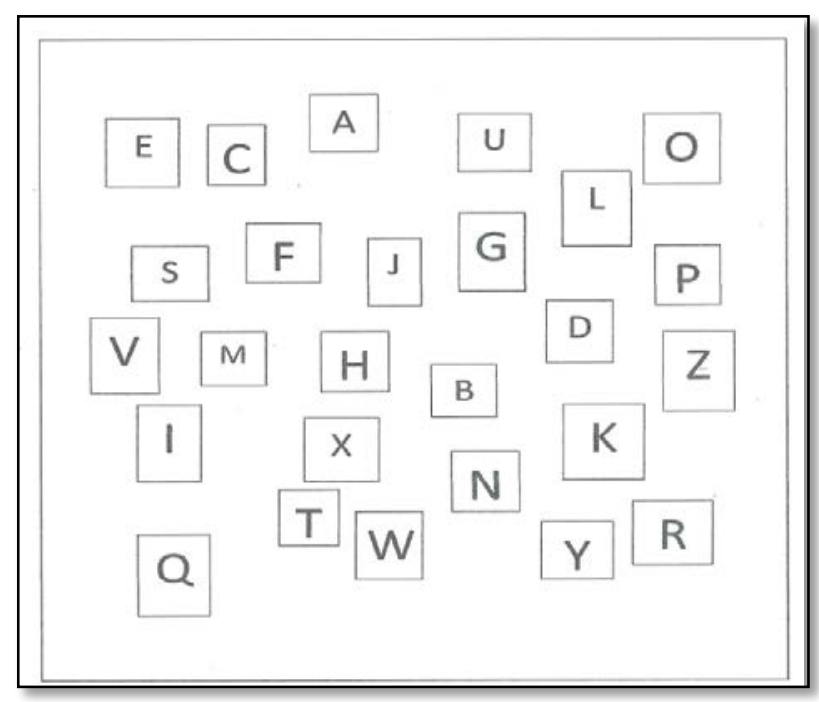

Sample 3: P4 RAN test.

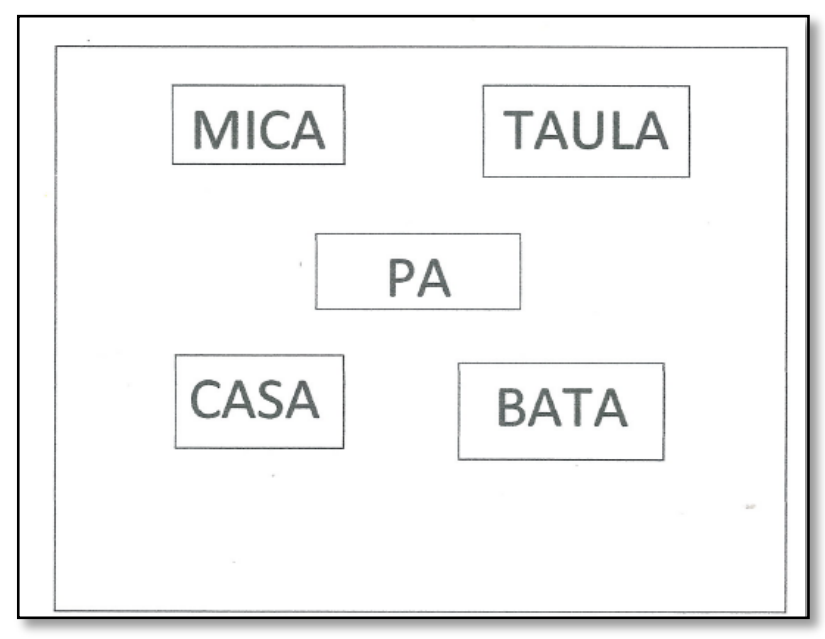

Sample 4: P4 PA test.

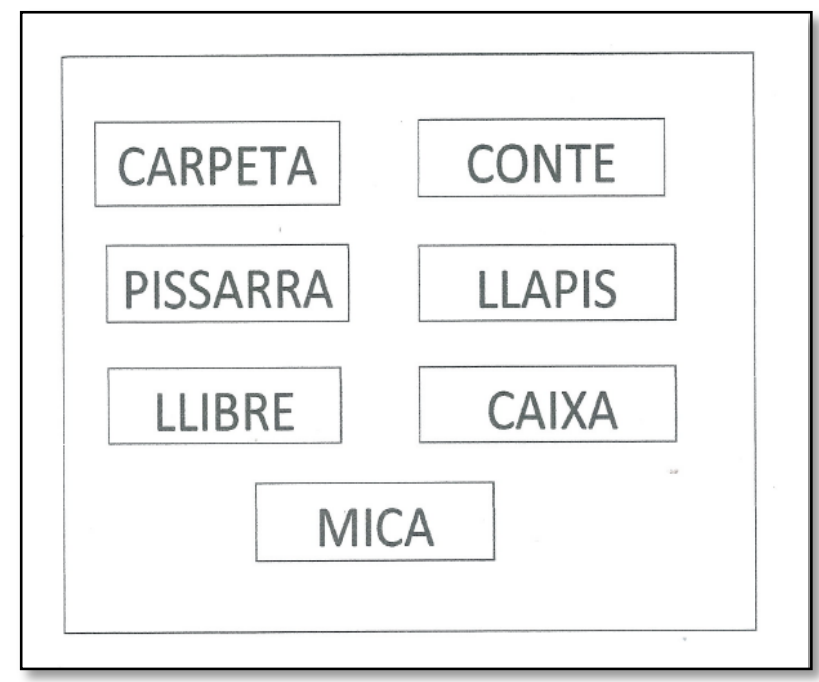

Sample 5: P5 RAN test.

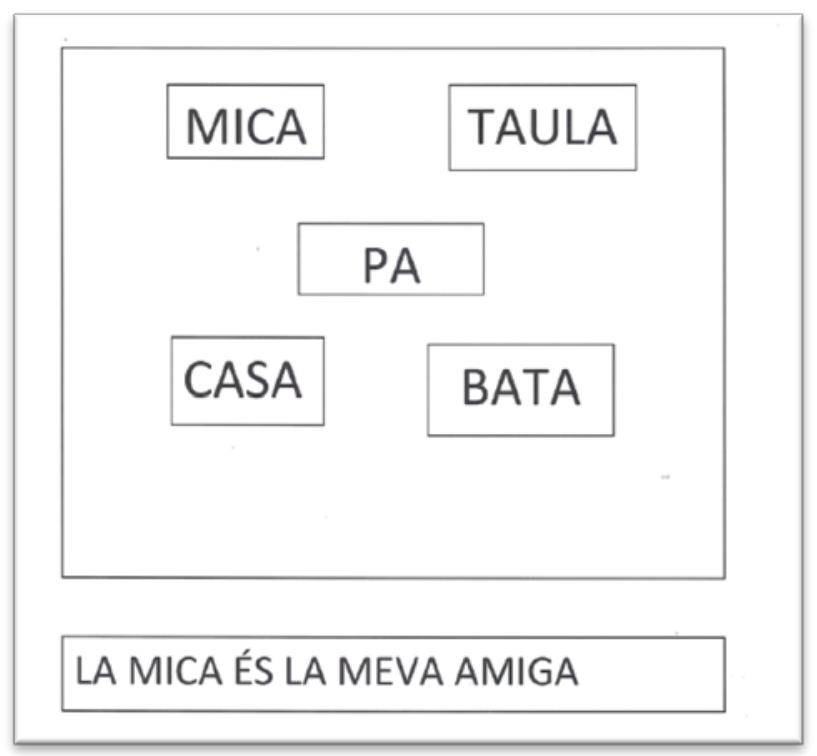

Sample 6: P5 PA test.

These tests, as has already been pointed out, are in line with the criteria of the teachers of the school where the test is carried out and, therefore, with the method. This method is based on the Model, known as the Double Cascade Route (DCR) [28] which aim is to ensure that the children, as they become familiar with the letters, also learn the sounds as well. But they are also shown an image which represents the sound, and furthermore, with Phonocolour a lot of work is done on this aspect as each of the vowels in Catalan has a colour, so they recognise the letter (the orthographic system) and the sound from the image (phonological system) but they also relate the word to the image (the semantic system). The following is an explanation of the three groups of tests, outlined above: 


\subsubsection{RAN test}

This test has been designed on the basis of the "Test for the early detection of reading and writing learning difficulties" [29] but designed for children at the early primary stage. In order to ensure that the adaptation is effective, teachers were asked about the level of learning that the children would need to have at the end of each year (even though in this school it is felt that evaluation has to be carried out at the end of the primary stage) in accordance with their own method of assessing the learning of reading and writing). As a result of this, different rubrics for each test were established depending on the group/class. The template for the test, for each year, would be as follows:

Table 1. Overall RAN tests used in each course

\begin{tabular}{|c|c|c|c|}
\hline $\begin{array}{c}\text { Academic } \\
\text { Year }\end{array}$ & P3 & P4 & P5 \\
\hline $\begin{array}{c}\text { Ran } \\
\text { Colours }\end{array}$ & Colours & Colours & Colours \\
\hline $\begin{array}{c}\text { Ran } \\
\text { Numbers }\end{array}$ & $1,2,3$ & $\begin{array}{c}1,2,3,4,5 \text { and } \\
6\end{array}$ & $\begin{array}{c}1,2,3,4,5,6,7,8,9 \\
\text { and } 10\end{array}$ \\
\hline Ran Letters & $\begin{array}{c}\text { The initials } \\
\text { of the } \\
\text { children in } \\
\text { the class }\end{array}$ & $\begin{array}{c}\text { All the letters } \\
\text { of the } \\
\text { alphabet }\end{array}$ & Significant words \\
\hline
\end{tabular}

\subsubsection{Phonological Awareness test}

The Bateria a la Lectura [30] was taken into account in the design. Even so, it was decided to remove the part of the RAN test that related to the recognition of words or syllables[29], and to do one part of it, only the part relating to recognition of phonemes, [22], [23], Phonological Awareness (PA) is one of the most important precursors; at the same time account was taken of sequence of acquisition,[31]. At the age of 4, approximately, children acquire the ability to distinguish between syllables, at 5 (approximately) the ability to reflect on the smallest linguistic units (intra-syllabic or rhyme) and at around 6 or 7 (approximately), at the beginning of the second stage of primary education and formal training in reading, they further develop this ability to think about the smallest units of the sentence.

Finally, as in the previous test, the teachers of the early primary stage at the school were consulted so as to make sure that the test would reflect the aims set for each of the three years of that cycle. In light of all this, the template for the test would be as follows:
Table 2. Overall PA test used in each course: Identifying letters and Reading Words

\begin{tabular}{|l|l|l|}
\hline \multicolumn{1}{|c|}{ P3 } & \multicolumn{1}{|c|}{ P4 } & \multicolumn{1}{c|}{ P5 } \\
\hline $\begin{array}{l}\text { Significant words: } \\
\text { the letters must be } \\
\text { identified }\end{array}$ & $\begin{array}{l}\text { Significant word: the } \\
\text { letters must be } \\
\text { identified. If they are } \\
\text { to be read. }\end{array}$ & $\begin{array}{l}\text { Reading the words } \\
\text { and the significant } \\
\text { sentence }\end{array}$ \\
\hline
\end{tabular}

\subsubsection{Aesthetic Quality Experience (AQE)}

In order for the pupils to be able to extract meaning, the perspective of the experience of aesthetic quality was invoked. For this reason, in the RAN test they were asked to look for the initials of their best friends or of the class teacher, or in the case of $\mathrm{P} 5$, to explain what they significant words suggested mean for them.

Table 3. Overall AQE tests (RAN) in each course

\begin{tabular}{|c|l|l|}
\hline P3 & \multicolumn{1}{|c|}{ P4 } & \multicolumn{1}{c|}{ P5 } \\
\hline $\begin{array}{l}\text { The initials of the } \\
\text { pupils in the class }\end{array}$ & $\begin{array}{l}\text { All the letters of the } \\
\text { alphabet }\end{array}$ & Significant words \\
\hline
\end{tabular}

As regards the Phonological Awareness test, it was suggested that the Aesthetic Quality Experience representation should be connected to the choose the word you like best, and that the children explain what these words mean for them. The explanations they offer are taken into account, and also the feelings that arise during the explanation.

Table 5. Overall AQE tests (PA) in each course

\begin{tabular}{|l|l|l|}
\hline \multicolumn{1}{|c|}{ P3 } & \multicolumn{1}{|c|}{ P4 } & \multicolumn{1}{c|}{ P5 } \\
\hline $\begin{array}{l}\text { Significant words. } \\
\text { They have to } \\
\text { explain which ones } \\
\text { are meaningful for } \\
\text { them }\end{array}$ & $\begin{array}{l}\text { Significant words. } \\
\text { The pupils have to } \\
\text { are meaningful for } \\
\text { them }\end{array}$ & $\begin{array}{l}\text { Reading the words } \\
\text { and the significant } \\
\text { sentencer The } \\
\text { pupils explain } \\
\text { what the meaning } \\
\text { is for them }\end{array}$ \\
\hline
\end{tabular}

In this way we obtain data relating to the AQE of the previous two tests.

\subsection{Rubrics}

The rubrics were created as an element to evaluate each of the tests and to assess how suitable they were for each of the three years. After consulting the tutors, there was some readjustment to bring them into line with the aims for each year, after which each rubric was validated. Some examples follow below:

Table 6. Rubric RAN colours P3

\begin{tabular}{|c|c|c|c|c|c|c|c|c|}
\hline $\begin{array}{c}\text { Number of } \\
\text { Errors }\end{array}$ & $\begin{array}{c}\text { ALL } \\
\text { OK }\end{array}$ & 1 ERROR & 2 ERRORS & 3 ERRORS & 4 ERRORS & 5 ERRORS & 6 ERRORS & $\begin{array}{c}\text { ALL } \\
\text { WRONG }\end{array}$ \\
\hline Scores & 7 & 6 & 5 & 4 & 3 & 2 & 1 & 0 \\
\hline
\end{tabular}

Table 7. Rubric RAN numbers P3

\begin{tabular}{|c|c|c|c|c|}
\hline Number of Errors & ALL OK & 1 ERROR & 2 ERRORS & 3 ERRORS \\
\hline Sores & 3 & 2 & 1 & 0 \\
\hline
\end{tabular}


Table 8. Rubric RAN letters P3

\begin{tabular}{|c|c|c|c|c|c|c|}
\hline $\begin{array}{c}\text { Number of } \\
\text { Errors }\end{array}$ & ALL OK & 1 ERROR & 2 ERRORS & 3 ERRORS & 4 ERRORS & 5 ERRORS \\
\hline Scores & 5 & 4 & 3 & 2 & 1 & 0 \\
\hline
\end{tabular}

Table 9. Rubric PA P4

\begin{tabular}{|c|c|c|c|c|}
\hline Number of Errors & ALL OK & 1 ERROR & 2 ERRORS & 3 ERRORS \\
\hline & $\begin{array}{c}\text { Reads or identifies all } \\
\text { the letters }\end{array}$ & $\begin{array}{c}\text { Reads or identifies the letters } \\
\text { of two words }\end{array}$ & $\begin{array}{c}\text { Reads or identifies the letters } \\
\text { of one word }\end{array}$ & $\begin{array}{c}\text { Does not read or identify the } \\
\text { letters of any of the words }\end{array}$ \\
\hline Scores & 3 & 2 & 1 & 0 \\
\hline
\end{tabular}

Table 10. Rubric AQE RAN P5

\begin{tabular}{|c|c|c|c|c|}
\hline Number of Errors & ALL OK & 1 ERROR & 2 ERRORS & 3 ERRORS \\
\hline & $\begin{array}{l}\text { The pupil identifies 3 words } \\
\text { from the list and explains } \\
\text { why they chose them and } \\
\text { what they mean for them }\end{array}$ & $\begin{array}{l}\text { The pupil identifies 2 words } \\
\text { from the list and explains } \\
\text { why they chose them and } \\
\text { what they mean for them }\end{array}$ & $\begin{array}{c}\text { The pupil identifies 1 } \\
\text { word from the list and } \\
\text { explains why they chose it } \\
\text { and what it means for } \\
\text { them }\end{array}$ & $\begin{array}{c}\text { The pupil fails to identify } \\
\text { any word with an object } \\
\text { that is meaningful to } \\
\text { him/her and cannot } \\
\text { explain what it means }\end{array}$ \\
\hline Scores & 3 & 2 & 1 & 0 \\
\hline
\end{tabular}

Table 11. Rubric AQE CF P5

\begin{tabular}{|c|c|c|c|c|}
\hline $\begin{array}{c}\text { Number of } \\
\text { Errors }\end{array}$ & ALL OK & 1 ERROR & 2 ERRORS & 3 ERRORS \\
\hline & $\begin{array}{l}\text { The pupil explains why they } \\
\text { have used or what the three } \\
\text { words on the list mean }\end{array}$ & $\begin{array}{l}\text { The pupil explains why they } \\
\text { have used or what two words } \\
\text { on the list mean }\end{array}$ & $\begin{array}{l}\text { The pupil explains why they } \\
\text { have used or what one word } \\
\text { on the list means }\end{array}$ & $\begin{array}{c}\text { The pupil fails to explain the } \\
\text { purpose or the meaning of } \\
\text { any of the words on the list }\end{array}$ \\
\hline Scores & 3 & 2 & 1 & 0 \\
\hline
\end{tabular}

\section{Analysis}

\subsection{Results by Academic Year and RAN Test}

\section{YEAR P3. 3 Years old}

\section{1) The rapid reading, or RAN test}

The RAN test is subdivided into 4 sub-tests: Total RAN, colours RAN, numbers RAN and letters RAN

a) The results of the Total RAN subtest (maximum 15 points minimum 0 , for an overall of 17 pupils: 10 boys and 7 girls) can be divided into three groups: a) it can be observed in the fact that there is a first group, 9/17 pupils who scored the maximum (15 points). b) there follows a second group, 3/17 pupils, with 14 points c) the rest, 5/17 pupils with 12-7 score respectively. In terms of gender, 10 boys and 7 girls, there are two groups of boys: a) those who obtained a maximum (score of 14 or 15), make up $80 \%$ of the total (8/10 pupils) and b) those who obtained 11 or 7 score make up $10 \%$. In the case of the girls, the percentage of those obtaining maximum (score 15), was $57.1 \%$ (much lower percentage than the boys) representing $4 / 7$ pupils.

b) In test 2, (maximum 7, minimum 0) RAN colours, in the first place, $58.8 \%$ obtain the maximum score of 7 points (10/17), in the second place $17.6 \%$ obtained 6 points (3/17) and $23.5 \% 5$ points (4/17). In terms of gender, $60 \%$ of the boys obtained 7 points $(6 / 10)$, $20 \%$ obtained 6 points (2/10) and 5 points and 20\% $(2 / 10)$ with the lowest range. In the case of the girls, $57.1 \%$ obtained the maximum score of 7 points (4/7), $14.3 \%$ obtained 6 points (1/7) and $28.6 \%$ scored 5 points (the lowest) 2/7 pupils.

c) The RAN numbers subtest, (maximum 3 minimum 0 ). In this test, $82.3 \%$ obtained the maximum score of 3 points (14/17), with 1 point (1/17) 5,88\% and 0 points (2/17) being $11,7 \%$. By gender, $90 \%(9 / 10)$ of the boys obtained the maximum score of 3 points, and $10 \% 0$ points $(1 / 10) .71 .4 \%$ of the girls scored 3 points (5/7), and $14.3 \% 1$ or zero points (2/7).

d) Finally, in the RAN (maximum 5, minimum 0) letters test, $64.7 \%$ scored the maximum 5 points (11/17), $11.8 \% 4$ points (2/17), $17.6 \% 3$ points (3/17) and finally $5.88 \%$ scored 2 points (1/17). By gender, $70 \%$ of the boys scored 5 points $(7 / 10)$. Of the remaining $30 \%, 10 \%$ score $4(1 / 10), 3(1 / 10)$ and 2 points $(1 / 10)$ each. In the case of the girls the percentages vary; only $57.1 \%$ score the maximum number of points (4/7), 14.3\% scored 4 points (1/7) and 28.6\% scored 3 points (2/7).

\section{2) The phonological awareness test or PA (maximum 3 , minimum 0)}

In the case of the PA test the percentages are very similar between the general test and when separated by gender. To 
be precise, $41.2 \%$ obtained 3 points (maximum), 11.8\% scored 2 points, $29.4 \%$ scored 1 point and $17.6 \%$ no points.

By gender, $40 \%$ of the boys scored 3 points (4/10), 10\% 2 points (2/10 pupils) and $50 \%$ (5/10 pupils) 1 point respectively. In the case of the girls, $42.9 \%$ scored 3 points (3/7 pupils), $14.3 \% 2$ points (1/7 pupil), $28.6 \% 1$ point ( 2 points) and $14.3 \%$ with zero points (1/7 pupil)

\section{3) The Aesthetic Quality Experiences test. (maximum 6, minimum 0)}

As regards the AQE test the amount is the same both generally and by gender. That is to say, $58.8 \%$ obtain 6 points (10/17 pupils), 17.6\% obtain 5 and 4 points respectively (3/17 pupils), and 5.9\% score 2 (1/17 pupil). By gender, $60 \%$ of the boys obtain the maximum score (6/10 pupils) of 6 points, 30\% score 5 points (3/10 pupils) and finally $10 \%$ score 4 (1/10 pupil). In the case of the girls, the scores are very similar at the top end. That is to say, $57.1 \%$ obtained the maximum score of 6 (4/7 pupils). But the remaining percentages are at the lower end of the scale: $28.6 \%$ obtain 4 points (2/7 pupils) and $14.3 \%$ obtain 2 points (1/7 pupil).

\section{P4. 4 years old.}

\section{1) The rapid reading or RAN test:}

When we analyse the overall (maximum 15, minimum 0) we observe that more than half the class, $66.7 \%$, obtains a maximum of 15 points (10/15), even though $13.4 \%$ with a score of 14 to 11 points (4/15), which means that, by and large, the competence level is high. By gender, 3 out of every 4 boys have the maximum level of achievement (15 points) resulting in 6/7 pupils and none of them scored the lowest marks, the child with the lowest mark scoring 13 representing (1/7 pupils). The same is not true of the girls, only $62.5 \%$ of whom obtained the maximum score (almost10 percentage points less than the boys) (5/8 pupils) and in addition $12.5 \%$ of the total number score 11 points (1/8)

2) In the colours test (maximum 3 , minimum 0 ) it is worth noting that almost the whole class, $86.7 \%$, scored 3 points (13/15), and a total of $13.3 \%$ scored with a low of 2 points (2/15). By gender, the results are very similar, as $85.7 \%$ of the boys scored the maximum 3 points $(6 / 7$ pupils), $14.3 \%$ scored $2(1 / 7)$ and in the case of the girls, $87.5 \%$ obtained 3 points (7/8) and $12.5 \%$ scored 2 points $(1 / 8)$.

3) In the numbers test (maximum 5 , minimum 0 ) a total of $93.3 \%$ obtained the maximum score of 5 points (15/15 pupils), and only $6.7 \%$ scored 3 points (1/15 pupils). If the results are studied by gender, the boys obtained a similar result to the overall percentage, in that $100 \%$ of them obtained the maximum score of 5 points, while $87.5 \%$ of the girls scored the maximum number of 5 points (7/8), and $12.5 \% 3$ points $(1 / 8)$.
4) With regard to the letters test (recognizing 7 or more letters is maximum), the results show that two-thirds of the pupils (66.7\%) recognised 7 or more letters and $33.3 \%$ only made 1 mistake. By gender, the girls, $62.5 \%$ obtained the maximum score of 7 points (5/8), but in the case of the boys, the average is different in that three quarters obtained 7 points (71.4\%) representing 5/7 pupils and $28.6 \%$ scored 6 points (2/7 pupils).

\section{2) The phonological awareness test (maximum 3, minimum 0)}

In the phonological awareness test, across the total sample of 15 children, we observe that $40 \%$ of the class obtained the maximum score of 3 points (6/15 pupils), while $46.7 \%$ scored 0 points (7/15 pupils). As for the pupils who obtained 1 or 2 points, they represent $6.7 \%$ of the total number (2/15). By gender, $43 \%$ of the boys scored 0 points (3/7 pupils) and $43 \%$ scored 3 points (2/7), with $14 \%$ obtaining 1 or 2 points (2/15). In the case of the girls, the percentage is equally divided between the two extremes: $50 \%$ obtained 0 points (4/8) and 50\% the maximum score of 3 points (4/8)

\section{3) The AQE test (maximum 6, minimum 0)}

With regard to the total AQE analysis across both the RAN and the PA tests, the results show that more than half the pupils, $53.3 \%$ obtained a maximum score of 6 points (9/15 pupils). $20 \%$ of the children scored 4 and 5 points (4/15) and $6.7 \%$ only one with 3 points (1/15 pupils). By gender, the results for boys and girls were significantly different. In the case of boys, only $42.9 \%$ obtained the maximum score of 6 points (3/7), while the figure for those scoring 4 or 5 was $28.6 \%$ (4/7) pupils. As for the girls, $75 \%$ obtained the maximum score of 6 points (6/8) pupils while $25 \%$ scored 0 points.

If the results are analysed in relation to the tests, it can be stated that, in the PA test $53.35 \%$ obtained the maximum score, while the remaining $46.7 \%$ scored either 1 or 2 points. When analysed by gender, we see that $57.2 \%$ of the boys obtained 1 or 2 points (28.6\% respectively) while $42.9 \%$ scored the maximum number of points. Finally, we see that more than half of the girls, $62.5 \%$, got the maximum number of points, followed by $25 \%$ with 1 point and $12.5 \%$ with 2 . As regards the RAN test, the overall results show that $93 \%$ of the pupils scored the maximum number of 3 points, and $6.7 \%$ scored 2 points. By gender, $100 \%$ of the boys scored 3 points, while $87.5 \%$ of the girls achieved the maximum score and $12.5 \% 2$ points.

\section{P5. 5 years old.}

\section{1) The RAN test}

In the total RAN test (maximum score 15 minimum 0 points). The number of pupils was 20, 8 boys and 12 girls. For the overall almost half of the pupils, 10/20 pupils 
scored 15 points (the maximum). Half of the remaining pupils, 23.8\%, scored second highest (14 points) and 19\%, 13 points third highest, while $9.5 \%$ got 12 points fourth highest. By gender, $50 \%$ of the boys obtained 15 or 14 points, second highest (25\% in each case, $4 / 8$ pupils). $37.5 \%$ scored 13 points (3/8 pupils) and $12.5 \% 12$ points (the lowest) with $1 / 8$ pupils. In the case of the girls, $84.6 \%$ scored 15 or 14 points (highest and second highest score for 10/12 pupils). As regards the rest of the girls, 7.7\% scored 13 points and the same number 12 points.

In the colours test (maximum score 5 minimum 0), 90.4\% achieved the maximum score of 5 points (18/20 pupils), and $4.8 \%$ both 4 points and 3 points (1/20 respectively). By gender, $75 \%$ of the boys scored obtained 5 points $(6 / 8$ pupils), $12.5 \%$ obtained 4 points and the same percentage 3 points (1/8 pupils respectively). $100 \%$ of the girls scored 5 points (12 girls)

In the numbers test (maximum score 5 minimum 0 ), the results show that $85.7 \%$ scored 5 points (17/20 pupils) and only $14.3 \%$ got 4 (3/20 pupils). By gender, in this case the results show the opposite pattern to the colours test, with $100 \%$ of the boys scoring the maximum of 5 points (8/8 pupils), while $76.9 \%$ of the girls achieved the maximum score (9/12 pupils), and $23.1 \% 4$ points ( $3 / 12$ pupils).

When it came to the words test (maximum score 5 minimum 0 ), the results show a very different pattern. Roughly two thirds of the pupils (61.9\%) achieved the maximum of 5 points (12/20 pupils) while $14.3 \%$ scored 4 points $2 / 20$ pupils and $23.8 \% 3$ points (6/20) pupils. By gender, the scores are distributed as follows: $37.5 \%$ scored 5 points ( $3 / 8$ pupils), $25 \%$ got 4 points (2/8 pupils) and $37.5 \% 3$ points ( $3 / 8$ pupils). The opposite is the case with the girls, with three quarters scoring the maximum number of points (75\%) (9/12 pupils), while $8.3 \%$ obtained 4 (1/12 pupils) and $16.7 \% 3$ points, $2 / 12$ pupils

\section{2) The Phonological Awareness test}

In the PA test (maximum 3 minimum 0), the results are similar to those in the previous section; that is to say, $95.2 \%$ achieved the maximum score (19/20 pupils) and only $4.8 \%$ got 1 point ( $1 / 20$ pupils). By gender, $100 \%$ of the boys obtained the maximum score of 3 points, while $92.3 \%$ of the girls achieved this result (11/12 pupils). $7.7 \%$ of the girls got 1 point ( $1 / 20$ pupils).

\section{3) The AQE test}

In this AQE test (maximum 6 minimum 0). For this academic year, the AQE results are noteworthy, as $95.2 \%$ of the pupils obtained the maximum score of 6 points (19/20 pupils), and only $4.8 \%$ got 4 points ( $1 / 20$ pupils). By gender, $100 \%$ of the boys scored the maximum points and $95 \%$ of the girls achieved the maximum score $(19 / 20$ pupils), while $5 \%$ of the latter obtained 4 points $(1 / 20$ pupils).

\section{Discussion}

In the following section we will discuss the results according to the academic Year. We will start with 3-year-old, then 4-year-old and then 5-year-old.

\subsection{P3}

As far as the general results of the RAN test are concerned, what is particularly striking is the division of the pupils in two groups: half of them are in the top end of the points range and the other half are at the lower end. These percentages are maintained, almost entirely, when the results are observed by gender we notice that the percentage of girls at the top end increases by almost 10 percentage points. This pattern is repeated in the colours and letters, but not in the numbers section, in which the top end percentage is over $70 \%$ in all cases. This is probably due to the learning methods being used for mathematics for the previous two academic years, during which children learn best through play and using their hands, as these methods are more motivating and, therefore, become experiences of aesthetic quality.

At this point it is worth pointing out that during the colours part of the test, one of the things that surprised us most is that more than half of the children did not always name the colours using the same language, that is to say, they mixed Catalan and Spanish (mainly) but they even used English as their first choice in identifying the colours. It is true, of course, that English is used frequently at this stage of primary education, and some activities are conducted exclusively in English. In this particular case, the speed was not counted as a restrictive value at all, since we observed that pupils needed more time to process and associate the label of the colour with the colour itself.

The previous pattern is repeated in the percentages for Phonological Awareness (PA). That is to say, the class is polarised towards the two extremes, with $50 \%$ of the class obtaining between 2 and 3 points while the other $50 \%$ score 1 or 0 points. This trend also seems to be repeated when the results are analysed by gender, though there is a slight tendency for the percentage to increase in the case of the girls, who outperform the boys by a little more than 7 points. It should be pointed out that the pupils in this class, when they were asked to name the letters that formed the words, found it more difficult to do so than when, in the RAN test, they were asked to find their own initials or those of the other names. They were more anonymous when it came to deciding which letter to choose and why than when they were given a word and had to identify the letters which formed it.

These percentages change significantly with the AQE test in which, broadly speaking, three quarters of the pupils scored 5 or 6 and only one of them obtained the minimum 1 point. When the results are analysed by gender, the differences are striking, in that we can observe entirely 
different patterns between boys and girls. In the case of the former, the results show that the tests were highly motivating and meaningful, as $90 \%$ scored between 5 and 6 points, and only one of them scored 4 points. In the case of the girls, fewer than $60 \%$ scored 6 points and the next significant percentage corresponds to those who scored 4 and finally, a little more than $14 \%$ get the lowest score of 2 . Thus we can see that there is room for improvement as regards the AQE results. In other words, the percentages for girls need to be improved so that they end up with a score similar to the boys, as this would mean that they would be more motivated and the tests would be more significant for them and their abilities.

\subsection{P4}

The results for this year turn out to be very different from the previous one. It is a group in which high marks were scored by the vast majority. To be precise, in general terms, at least three quarters of the pupils obtain top end scores. In the case of the RAN test, for example, the percentages are comparable to those corresponding to words. But, by contrast, in the colours and numbers tests, the percentage of the pupils who obtained the highest score exceeded, in every case, $85 \%$. This is because colours are the focus of a lot of attention from very beginning of primary education, and are taught through 3 languages, Catalan, Spanish and English, and it also turns out that the pupils with the lowest marks across the categories also obtain low scores for colours, however this low score did not have to do with the use of a specific language usage (these pupils are bilingual for Catalan and Spanish) and more to do with the abstract notion of the label colour. There are 2 pupils who score a very low mark in both colours and numbers, but not in letters.

The results of the PA test are very polarised. We believe that the fact of the test being carried out in February might be one of the contributing factors as in the middle of the academic year, not all the pupils have reached a sufficient level of maturity in the learning process. Moreover, the greatest disparity is observed when analysing the results by gender, as the girls are sharply divided between $50 \%$ with the maximum score ( 3 points) and the same percentage with 0 points. In the case of the boys the disparity is not so sharp, although the highest percentage corresponds to those with 0 points. When we look at the two specific cases mentioned above, we see that one of them scored 2 points (out of a maximum of 3 ) while the other achieved the maximum score. This might be due to the words being more meaningful to them than the colours, as it in the latter that the lowest results were obtained, or perhaps it was because the colours test was done first, and the person who conducted the tests was not the pupils' regular teacher.

In the case of the AQE tests, the results are much more satisfactory, as in every case, at least three quarters of the pupils achieved the maximum score (5 or 6 points). It should be pointed out that, both in the case of the boys in particular and the pupils in general, the minimum score is 4 points, though $25 \%$ of the total number of boys scored 3 points. Broadly speaking, however, it is felt that there are several reasons why the results in this test are so good. The first of these is that it was the last test to be carried out, so the children were more relaxed, and secondly, the words that they chose were very meaningful for them, like the "bread" that they have for breakfast, or the "doll" (their word for their little rag-doll) which has a part to play in many of their classroom activities or the "bata" (the tunic) that they wear every day, are elements that they touch, see or hear every day (as are "taula” (table) or "casa” (house).

It is also worth pointing out that with the word "mica" (little) all the children's faces lit up and they all pointed out where the doll was at that moment (see below Picture). Therefore, it can be concluded that bringing teaching into the children's personal lives, and especially adapting it so that it becomes meaningful to them, seems to be way to develop most fully the potential that each pupil possesses.

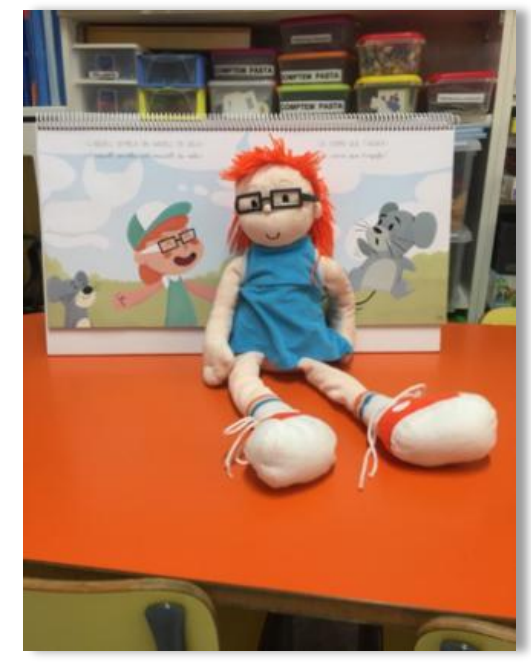

Mica. The doll that plays a role in many of the learning activities.

\section{3. $\mathrm{P5}$}

In the school where these tests were carried out, this is a key academic year in achieving the objectives with regard to the mechanical task of reading (always realising, of course, that there is still time until the end of the first cycle of primary education) and in fact all the activities carried out during this stage are aimed at achieving this objective. As regards the results of the RAN test, the first thing to notice is the fact that it is the group in which the best results are achieved in the general test, with $3 / 4$ of the pupils achieving the maximum score (14 or 15 points), even though this percentage is not obtained if we only look at the result for boys (the result being $50 \%$ in their case).

In the colours and words tests, the same pattern can be observed, as the boys tend to achieve lower scores, with a difference of 25 percentage points, than the girls in the 
former, and more than 40 percentage points in the latter. This is not the case in the numbers test, in which it is the highest percentage of the boys who score the maximum number of points ( $100 \%$ of them, in fact).

The PA tests are interesting because they show a clear tendency towards homogenisation in the pupils' acquisition of knowledge, as both the overall results and the results by gender show that at least $75 \%$ of the pupils achieved the maximum score of 3 points. This is very positive and relevant, as it indicates that, except in one of two specific instances (little girl number 3 for example) the rest of the group is shown to have made significant progress in the process of learning to read and write, to the point where joint writing began to be introduced last week (after the results of the tests had been assessed).

Last, but not least, we have the AQE assessment. In this case, the results are extremely satisfying because whether we look at them generally or by gender, in all three academic years, the percentage achieving the maximum score is over $90 \%$, with only one pupil scoring less than 2 points below the maximum score of 6 , the pupil in question being girl number 3 referred to above. In this course, there are 5 pupils who are particularly worthy of note.

The aim behind these tests was to observe the level of reading and writing competence in the early primary stage, but it was also aimed at exploring the extent to which AQE factors influence this learning process. The fact of being able to assess a pupil's motivation, or lack of motivation, is a determining factor in redirecting the learning of each pupil in line with their abilities. For this reason, it was suggested to the school directors that they repeat these tests once every term so as, in the first place, to be able to track the development of each pupil, so that they continue to grow in a positive direction and, secondly, to be able to adapt the contents of each child's knowledge in proportion to their abilities and thus to make their learning meaningful. If this objective can be met, the predisposition of each child to engage in the learning process will be much better.

\section{Conclusions}

The challenge facing us in this project was to determine how the creation of aesthetic quality experiences could enhance the acquisition of reading skills on the part of children in P3, P4 and P5 in a semi-private school. With this aim in mind, two specific objectives were established.

The first general objective was met in that it was possible to determine the level of learning achieved, as in $\mathrm{P} 3$, as the overall result of the RAN test was that on average more than 50\% achieved the maximum score, with two thirds of the pupils getting the maximum in the reading test. In the Phonological Awareness (PA) test, a little over $40 \%$ of the pupils achieved the learning aims of the academic year (learning the letters making up the names of their classmates), which suggests that, when the tests were conducted in the month of February, there was still plenty of opportunity for these percentages to be increased. As for P4, the RAN results were very positive, as more than $66 \%$ achieved the learning aims set for them, and $40 \%$ have begun to read words, as was also demonstrated by the PA test. In P5, the results of the RAN the number of pupils obtaining the maximum score fell short of $50 \%$; however, more than $95 \%$ showed that they had acquired sufficient knowledge to be able to read short sentences,

As regards the 2nd objective, the tests were very illuminating in this regard; that is to say, they clearly showed that when the learning process becomes an AQE, the results obtained are much more positive, as by nature young children display a great deal of curiosity about a vast range of things and, if this inherent motivation can be guided at an individual level at school, the results will be remarkable.

To conclude, the two general objectives set for this study demonstrate that learning can occur in many ways, and at this stage reading remains a mechanical process, but if this process is turned into an experience of aesthetic quality the foundation will be laid for future learning, and a larger percentage of pupils will acquire a much higher level of motivation, which will ensure that, in the first place, their first engagement with the learning process will be entirely positive.

\section{REFERENCES}

[1] J, Dewey. Democracia y Educación. Buenos Aires. Ed. Morata, 1916.

[2] M, F, Lara. Anàlisis de les dificultats de la lectura a partir dels models evolutius causals. EDUCAT, blog de psicopedagogia, 2013. https://www.educat.cat/blog/analiside-les-dificultats-de-la-lectura-a-partir-dels-models-evoluti us-causals/

[3] J, Manson and J, P, Stewart, J.P (1990. Emergent literacy assessment for instructional use in kindergarden. In. L.M Morrow and J.K Smith (Ed), Assessment for Instruction In Early Literacy, Englewood Cliffs, NJ: Prentice-Hall, pp. 155-175, 1990.

[4] G, J, Whitehurst and C, J, Lonigan. Child development and emergent literacy. Child development, vol 69(3), pp. 848-872, 1998.

[5] M, Sénechal, J-A, Lefevrer, B, L, Smith-Chant, K, V, Colton. On Refining Theoretical Models of Emergent Literacy The Role of Empirical Evidence, vol 39 5, pp. 439-460, 2001.

[6] M, S, C, Gallego and Serrano. Los prerrequisitos lectores. III Congreso Internacional de Lectoescriptura. Morelia (México), 23-25 de Marzo, 2006.

[7] Beltran, López and Rodríguez (2006). Precursores tempranos de la lectura: educación infantil i primer curso de primaria. En B, Gallardo, C, Hernández and V, Moreno. (Eds), I Congresos Nacional de Lingüística Clínica Valencia: Universitat de València, pp. 18-26, 2006 
[8] National Early Reading Panel, 2009.https://www.nichd.nih. gov/publications/product/346

[9] Currículum i Orientació del segon cicle d’Educació Infantil: Currículum del segon cicle de l'educació infantil - Decret 181/2008 DOGC núm. 5216, 2016.

[10] A, Ardilla. ¿Qué puede localizarse en el cerebro? Ciencia Cognitiva: Revista Electrónica de Divulgación vol 2:2, pp. 53-55. Barcelona. Avesta.2008.

[11] Andreu i Barrachina et al. L’adquisició de la lectura i les seves dificultats, UOC: Psicologia, pp. 27, 2013.

[12] I, Sanmillan. Evolución de los factores implicados en la adquisición y desarrollo de la lectoescriptura en niños de 4 a 7 años y surealización con dos métodos de enseñanza de la lectura. Tesis. Universitat de Valencia. Valencia, 2016.

[13] M, P, Lebrero and M, T, Lebrero. (1995). Fundamentación teórica y enseñanza de la lectura y la escritura. Aproximación al lenguajeescrito y evaluación de materiales. Madrid. UNED, 1995.

[14] P, Sellés. Elaboración de una de habilidades relacionadas con el desarrollo inicial de la lectura (BIL 3-6). Tesis. Universitat de Valencia. Valencia, 2008

[15] J, E, Jiménez, R, Guzmán, R, Ortiz, A, Díaz, A, Estévez, E, Gacía, I, Hernández- Valle, Muñetón, Mercedes, F, Naranjo, M, Rodrigo, C, Rodríguez and E, Rojas. Validez discriminante de la bateria multimèdia Sicole-R- Primaria para la evaluación de procesos cognitives asociados a la dislexia. Revista de Investigación Educativa, vol 27(1), pp. 49-71, 2009.

[16] L, E, Cutting and M, Denckla. History and significance of rapid automatized naming. Annals of Dyslexia, vol 49, pp. 29-42, 1999.

[17] J, R, Kirby, R, K, Parrilla and S, L, Pfeiffer. Naming speed and phonological awareness as predictors of reading development. Journal of Education Psychology, vol 95, pp. 453-464, 2003.

[18] F, R, Mais, L, M, Doi and B, Bhadha, B. Naming speed, phonological awareness, and orthographic knowledge in second graders. Journal of Learning Disabilities, vol 33, pp. 325-333, 2000.

[19] C, Schatschneider, J, M, Fletcher, D, J, Francis, C, D, Carlson and B, R, Foorman. Kindergarden prediction of Reading skills: A longitudinal comparative analysis. Journal of Education Psichology, 96, 265-282, 2004.

[20] M, Aguilar, J, Navarro, I, Menacho, A, Alcale, E, Marchena and P, Ramiro. Velocidad de nombrar y conciencia fonológica en el aprendizaje inicial de la lectura. Psicothema, vol 22 (3), pp. 436-442, 2010.

[21] F, Gomez- Velazquez, A, González- Garrido, D, Zarabozo and M, Amano. La velocidad de denominación de letras. El major predictivo temprano del desarrollo lector en espanyol. Revista Mexicana de Investigación Educativa, vol 15 (46), pp. 823-847, 2010.

[22] C, J, Lonigan and T, Shanahan, T. Executive Summary of Developing Early Literacy: Report of the National Early Literacy Panel. A Scientific Synthesis of Early Literacy Development and Implications for Intervention. Washington, DC: National Institute for Literacy, 2009.

[23] J, Thompson and T, Hogan. Future advances in the early detection of reading risk: Subgroup, dynamic relations, and advanced methodologies. Epilogue Special Edition Advances in the Early Detection of Reading Risk. Journal of Education Psychology, vol 84 3, pp. 364, 2009.

[24] E, S, Norton and M, Wolf, M. Rapid automatized naming (RAN) and reading fluency: Implications for understanding and treatment of reading disabilities. Annual review of psychology, vol 63, pp. 427-452, 2012.

[25] J, C, González. Perspectivas contemporáneas sobre la cognición: categorización, percepción y conceptualización. México: Siglo XXI, Universidad Autònoma del Estado de Morelos, 2006.

[26] R, Rodríguez, ¿Kant o Nietzsche? ¡Dewey! El idealismo naturalista y democrático de el arte como experiencia. Fedro, revista de estética y teoría de las artes, vol 2, pp. 51-69, 2004.

[27] R, Stake. The art of case study research. NY. Sage, 1995.

[28] M, Coltheart. Dual route and connectionist models of reading: an overview. London Review of Education, vol 4 (1)1, pp.5-17, 2006.

[29] Cuetos et al. Test de detención temprana de las dificultades en el aprendizaje de la lectura y escritura .Currículum i Orientació del segon cicle d’Educació Infantil (2016): Currículum del segon cicle de l'educació infantil - Decret 181/2008 DOGC núm. 5216, 2015.

[30] P, Sellés. Batería de inicio a la lectura (bil 3-6): diseño y características psicométricas. Universidad de Valencia.Bord on vol 2, pp. 137-160, 2010.

[31] S, Delfior and F, Serrano. Processos Fonológicos Explícitos e Implícitos. Lectura y Dislexia, 2011. https://www.researchgate.net/publication/277264041_Proce sos_Fonologicos_Explicitos_e_Implicitos_Lectura_y_Disle xia 